\title{
Variation in Photosynthetic Membrane and Pigment Content with Light Intensity for Anacystis nidulans Grown in Continuous Cultures
}

\author{
By HANS CHRISTIAN UTKILEN, * TORMOD BRISEID AND \\ BENNY ERIKSSON
}

Botanical Institute, University of Oslo, P.O. Box 1045, Blindern, Oslo 3, Norway

(Received 10 November 1983)

Photosynthetic membrane and chlorophyll content of the cyanobacterium Anacystis nidulans
were determined after growth at different light intensities in $\mathrm{Mg}^{2+}-$ limited and non- $\mathrm{Mg}^{2+}$
limited continuous cultures. Decreasing the light intensity from 445 to $31 \mu \mathrm{E} \mathrm{m}^{-2} \mathrm{~s}^{-1}$ resulted in
a threefold increase of chlorophyll per unit cell volume. The photosynthetic lamellar structure,
on the other hand, increased twofold under the same conditions. The specific chlorophyll
content of the photosynthetic membrane increased when the light intensity was decreased from
445 to $282 \mu \mathrm{E} \mathrm{m} \mathrm{m}^{-2} \mathrm{~s}^{-1}$ and was constant at lower light intensities. The results indicate that the
maximum chlorophyll content in the thylakoids of $A$. nidulans was about $1.5 \mathrm{fg} \mu \mathrm{m}^{-2}$, which
means that the membrane contained 1 chlorophyll molecule per nm $\mathrm{nm}^{2}$ under these conditions.

\section{INTRODUCTION}

Allen (1968) showed that the amount of photosynthetic lamellar structure in Anacystis nidulans was directly proportional to the chlorophyll content, when light intensities of $100 \mathrm{or} 1000 \mathrm{ft}-$ candle were used. By using different light intensities and qualities for growth of $A$. nidulans in $\mathrm{K}^{+}$- or $\mathrm{Mg}^{2+}$-limited chemostats, Briseid (1980) obtained results indicating that the membrane chlorophyll content might vary in this organism at higher light intensities.

The present study evaluates the chlorophyll content of the photosynthetic lamellar structure in $A$. nidulans grown in continuous cultures fed with 5 or $10 \mu \mathrm{M}-\mathrm{Mg}^{2+}$ and light intensities ranging from 31 to $445 \mu \mathrm{E} \mathrm{m}^{-2} \mathrm{~s}^{-1}$ (roughly 186 to $2975 \mathrm{ft}$-candle). The chlorophyll density in the membranes was estimated by a combination of quantitative biochemical and ultrastructural techniques.

\section{METHODS}

Organism. Anacystis nidulans strain UTEX 625 of the Culture Collection of Algae, Department of Botany, University of Texas, was used.

Growth conditions. The organism was grown in continuous cultures fed with a modified medium C (Utkilen, 1982), containing 5 or $10 \mu \mathrm{M}-\mathrm{Mg}^{2+}$, at a dilution rate $(D)$ of $0.09 \mathrm{~h}^{-1}$. The culture fed with $5 \mu \mathrm{M}-\mathrm{Mg}^{2+}$ was $\mathrm{Mg}^{2+}$ limited, while the culture fed with $10 \mu \mathrm{M}-\mathrm{Mg}^{2+}$ was not $\mathrm{Mg}^{2+}$-limited (Utkilen, 1982).

The culture vessels were placed in a waterbath $\left(40^{\circ} \mathrm{C}\right)$ between two ranks of four fluorescent tubes (Philips TL AK 40/W 33). This gave an incident irradiation of $445 \mu \mathrm{E} \mathrm{m}^{-2} \mathrm{~s}^{-1}$ from each side. The light intensities were measured with a LI 1854 Quantum/Radiometer/Photometer (Lambda Instruments Corporation, U.S.A.). Different light intensities were obtained by placing sheets of white paper between the waterbath and the fluorescent tubes. All light intensities given in this paper are those obtained from one side.

Estimation of chlorophyll density in the membranes. The cells were prepared for electron microscopy by a modification of the procedure used by Allen (1968). They were first treated with unbuffered $\mathrm{KMnO}_{4}(1.5 \%, \mathrm{w} / \mathrm{v})$ for $10 \mathrm{~min}$. After rinsing with distilled water and dehydration in a graded series of ethanol/water, the samples were treated with propylene oxide for $2 \times 5 \mathrm{~min}$ and left overnight in propylene oxide/Spurr $(3: 1)$ (Spurr, 1969). Next day this was exchanged for pure, fresh Spurr, which was polymerized at $70^{\circ} \mathrm{C}$. Sections $70 \mathrm{~nm}$ thick, made by an 
Ultratome 111 (LKB, Bromma, Sweden) using a diamond knife, were placed on 25 mesh carbon-coated grids and examined in a Jeol $100 \mathrm{C}$ electron microscope (JEOL Ltd, Japan) at $80 \mathrm{kV}$.

Electron micrographs of $30000 \times$ magnification were used to estimate the relation between the surface area of photosynthétic membrane $\left(A_{\mathrm{Phm}}\right)$ and cell volume $(V)$ as described by Weibel (1969). A simple square lattice consisting of 10 horizontal and 14 vertical lines (test lines) at a distance of $15 \mathrm{~mm}$ was placed, in a fixed position, on each micrograph. The surface of this lattice was always smaller than the area of the micrographs.

The relation between $A_{\mathrm{Phm}}$ and $V$ is then given by:

$$
A_{\mathrm{Phm}} / V=\left(2 \times I_{\mathrm{Phm}(\text { tota) })}\right) /\left(L \times P_{\mathrm{i}} / P_{\text {total }}\right)
$$

where $L$ is the total length of test lines ( $140 \mu \mathrm{m}$ in this case), $P_{\mathrm{i}}$ is the number of test points (intersections between test lines) covering the cells, $P_{\text {total }}$ is the total number of test points in the lattice (140 in this case), and $I_{\mathrm{Phm} \text { (total) }}$ is the total number of intersections between test lines and the photosynthetic membrane.

To compensate for estimation errors caused by the invisibility of membrane profiles oriented obliquely to the axis of the electron beam, the method of Reith (1977), developed for estimation of the relation between surface of cristal-membranes and mitochondrial volume, was used as follows:

$$
I_{\mathrm{Phm} \text { (total) }}=I_{\mathrm{Phm} \text { (distinct) }} \times K
$$

where $I_{\mathrm{Phm} \text { (distinct) }}$ is the number of intersections between test lines and distinct photosynthetic membrane. The value of $K$ was found by means of the cytoplasmic membrane, on the assumption that the relation between total and distinct photosynthetic membrane is the same as that between total and distinct cytoplasmic membrane. The total intersection between test lines and cytoplasmic membrane can always be found even when it is indistinct, i.e. obliquely oriented, since this membrane entirely surrounds the cell. The value of $K$ found in this way was used to calculate the corrected ' $I_{\mathrm{Phm} \text { (total). }}$

After determining cell number, mean cell volume $\left(\mu \mathrm{m}^{3}\right.$ per cell) and chlorophyll content ( $\mathrm{fg}$ per cell), the specific chlorophyll content of the photosynthetic membrane is given by:

$$
\text { Chlorophyll } / A_{\mathrm{Phm}}=\left(\text { chlorophyll } \times L \times P_{\mathrm{i}}\right) /\left(V \times 2 \times{ }^{\prime} I_{\mathrm{Phm} \text { (total) }} \times P_{\text {total }}\right)
$$

About 15 micrographs, each with about 25 cells, were examined from every light intensity.

Analytical methods. These were as previously described (Utkilen, 1982).

\section{RESULTS AND DISCUSSION}

When examining the photosynthetic membrane and chlorophyll content of $A$. nidulans grown at different light intensities, two continuous cultures were used. One culture was fed with $5 \mu \mathrm{M}$ $\mathrm{Mg}^{2+}$, and has been shown to be $\mathrm{Mg}^{2+}$-limited at $365 \mu \mathrm{E} \mathrm{m}^{-2} \mathrm{~s}^{-1}$ (Utkilen, 1982). The other culture, which was fed with $10 \mu \mathrm{M}-\mathrm{Mg}^{2+}$, has been shown to be influenced by another limitation, which could be light (Utkilen, 1982). These two cultures were therefore compared in order to see if the $\mathrm{Mg}^{2+}$-limited conditions used would influence chlorophyll and photosynthetic membrane synthesis.

At $445 \mu \mathrm{E} \mathrm{m}^{-2} \mathrm{~s}^{-1}$ the steady-state dry weight was about $180 \mu \mathrm{g} \mathrm{ml}^{-1}$ in the culture fed with $10 \mu \mathrm{M}-\mathrm{Mg}^{2+}$ and about $100 \mu \mathrm{g} \mathrm{ml}^{-1}$ in the culture fed with $5 \mu \mathrm{M}-\mathrm{Mg}^{2+}$. However, at $103 \mu \mathrm{E} \mathrm{m}^{-2} \mathrm{~s}^{-1}$ the steady-state biomass was about $65 \mu \mathrm{g} \mathrm{ml}^{-1}$ in both cultures, and a further decrease in light intensity to $31 \mu \mathrm{E} \mathrm{m}^{-2} \mathrm{~s}^{-1}$ resulted in the same linear decrease in biomass for both cultures. These results show that growth was limited to the same extent in both cultures below $103 \mu \mathrm{E} \mathrm{m}^{-2} \mathrm{~s}^{-1}$. If $\mathrm{Mg}^{2+}$ was still the limiting factor below this light intensity, one would expect a different steady-state biomass in cultures fed with 5 and $10 \mu \mathrm{M}-\mathrm{Mg}^{2+}$. Since this was not the case, and light was the only growth factor that had been changed, it was reasonable to conclude that both cultures were light-limited below $103 \mu \mathrm{E} \mathrm{m}^{-2} \mathrm{~s}^{-1}$.

At $445 \mu \mathrm{E} \mathrm{m}^{-2} \mathrm{~s}^{-1}$ the chlorophyll content was $7 \mathrm{fg}$ per unit $\left(\mu \mathrm{m}^{3}\right)$ cell volume regardless of the $\mathrm{Mg}^{2+}$ concentration in the medium, and it increased to $22 \mathrm{fg} \mu \mathrm{m}^{-3}$ in both cultures upon decreasing the light intensity (Fig. 1). These results indicate that the maximum chlorophyll content of $A$. nidulans under the conditions used was $22 \mathrm{fg}_{\mu \mathrm{m}^{-3}}$, since the cultures were lightlimited below $103 \mu \mathrm{E} \mathrm{m}^{-2} \mathrm{~s}^{-1}$ (see above) and the organism therefore should be saturated with respect to chlorophyll. The results also show that the $\mathrm{Mg}^{2+}$-limited $(5 \mu \mathrm{M})$ conditions used did not influence the chlorophyll content, since this was independent of the $\mathrm{Mg}^{2+}$ concentration in the feed medium. 


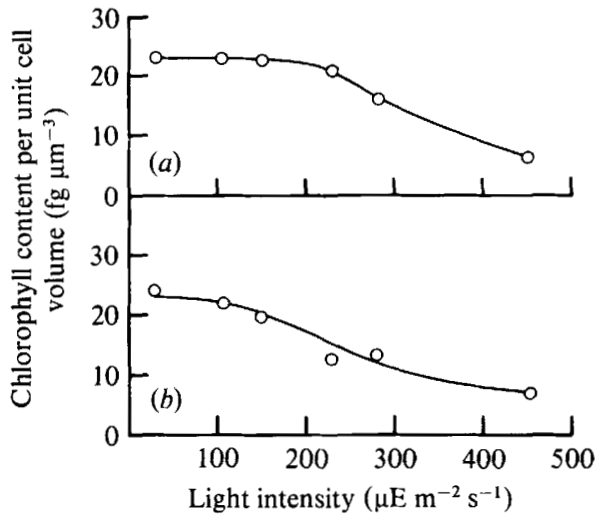

Fig. 1.

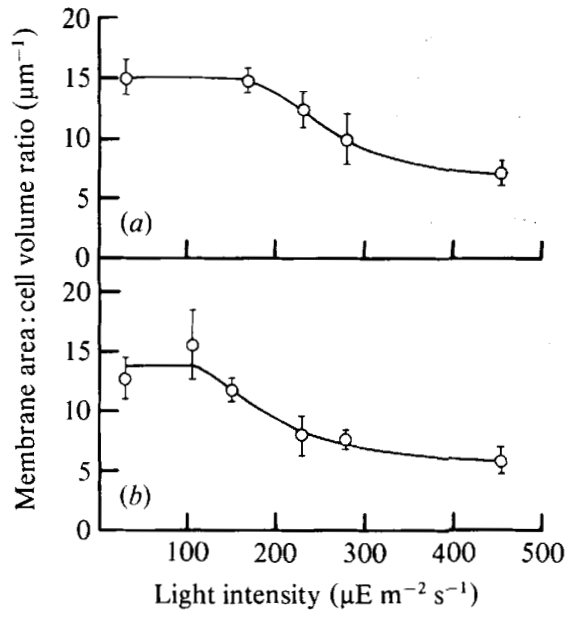

Fig. 2.

Fig. 1. Variation with light intensity in chlorophyll per unit cell volume, for $\dot{A}$. nidulans grown in continuous cultures $\left(D=0.09 \mathrm{~h}^{-1}\right)$ fed with $(a) 10 \mu \mathrm{M}-\mathrm{Mg}^{2+}$ or $(b) 5 \mu \mathrm{M}-\mathrm{Mg}^{2+}$. The data are average values obtained from three samples.

Fig. 2. Variation with light intensity in photosynthetic membrane area per unit cell volume, for $\boldsymbol{A}$. nidulans grown in continuous cultures $\left(D=0.09 \mathrm{~h}^{-1}\right)$ fed with $(a) 10 \mu \mathrm{M}-\mathrm{Mg}^{2+}$ or $\left(\right.$ b) $5 \mu \mathrm{M}-\mathrm{Mg}^{2+}$. The bars represent S.D.

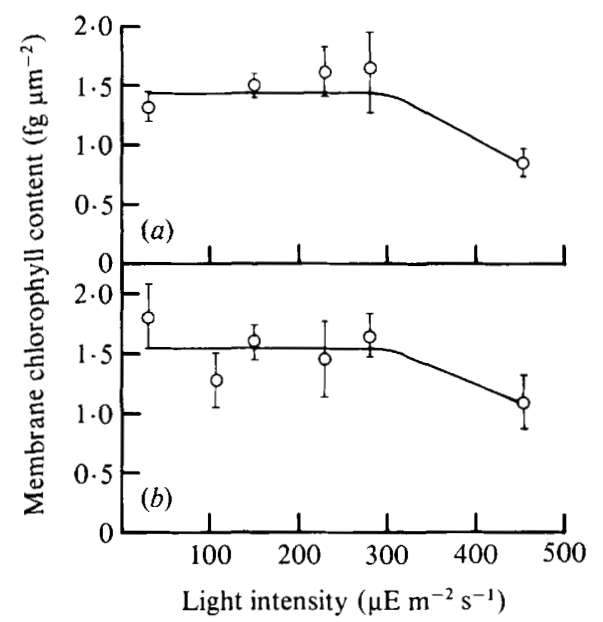

Fig. 3. Variation with light intensity in specific chlorophyll content of the photosynthetic lamellar structure in $A$. nidulans grown in continuous cultures $\left(D=0.09 \mathrm{~h}^{-1}\right)$ fed with $(a) 10 \mu \mathrm{M}-\mathrm{Mg}^{2+}$ or $(b)$ $5 \mu \mathrm{M}-\mathrm{Mg}^{2+}$. The bars represent S.D.

The culture fed with $10 \mu \mathrm{M}-\mathrm{Mg}^{2+}$ reached the maximum chlorophyll content at higher light intensities than the culture fed with $5 \mu \mathrm{M}-\mathrm{Mg}^{2+}$ (Fig. 1). This was presumably due to the fact that its biomass was higher than for the culture fed with $5 \mu \mathrm{M}-\mathrm{Mg}^{2+}$ and therefore the light conditions in the $10 \mu \mathrm{M}-\mathrm{Mg}^{2+}$ culture were actually different from those in the $5 \mu \mathrm{M}$ culture.

The relation between photosynthetic membrane area and mean cell volume increased up to a factor of 2 with decreasing light intensity for both cultures (Fig. 2). As observed for chlorophyll, the maximum membrane content was reached at higher light intensities in the culture fed with $10 \mu \mathrm{M}$ than in the one fed with $5 \mu \mathrm{M}-\mathrm{Mg}^{2+}$. 
Since there was a threefold increase in chlorophyll per unit cell volume while the membrane content was only doubled, there must have been an increase in chlorophyll per unit membrane area. The relation between chlorophyll and membrane content (Fig. 3) revealed that the increase in chlorophyll per unit membrane area occurred between 445 and $282 \mu \mathrm{mE} \mathrm{m}^{-2} \mathrm{~s}^{-1}$ only, while it was constant at lower light intensities. The results (Fig. 3) indicate that the maximum amount of chlorophyll per unit membrane area was about $1.5 \mathrm{fg} \mathrm{m}^{-2}$. From this value the maximal density of chlorophyll molecules per unit membrane area was calculated to be 1 chlorophyll molecule per $\mathrm{nm}^{2}$.

Allen (1968) found a constant chlorophyll content in the photosynthetic membrane below $145 \mu \mathrm{E} \mathrm{m}^{-2} \mathrm{~s}^{-1}$ (1000 ft-candle), which is in accordance with our results, but she did not examine the effect of higher light intensities. Our results show that $\boldsymbol{A}$. nidulans is able to vary the specific chlorophyll content of the membrane to a large extent at high light intensities. It increased by about $70 \%$ in the culture fed with $10 \mu \mathrm{M}-\mathrm{Mg}^{2+}$ when the light intensity was decreased from 445 to $282 \mu \mathrm{E} \mathrm{m}^{-2} \mathrm{~s}^{-1}$, and by about $40 \%$ in the other culture. The large discrepancy between the two cultures is most probably caused by the large errors in the estimation of specific membrane content (Fig. 2). In spite of this, the conclusion from these results is that $A$. nidulans varies the specific chlorophyll content in the thylakoids at high light intensities, while there is a constant content at moderate or low light intensities.

Thus $A$. nidulans seems to decrease its chlorophyll content by first decreasing the photosynthetic lamellar structure to a certain level, and then, when this membrane level is reached, the chlorophyll content in the membrane decreases. The same mechanism might also work for other cyanobacteria.

The authors thank Professor P. Halldal and Dr T. Barnard for critical reading of the manuscript.

\section{REFERENCES}

Allen, M. M. (1968). Photosynthetic membrane system in Anacystis nidulans. Journal of Bacteriology 96, 836-841.

BRISEID, T. (1980). Kalium begrenset vekst av Anacystis nidulans. Cand. real. thesis, University of Oslo, Norway.

ReITH, A. (1977). Problems in the estimation of surface densities (S.D.) of biomembranes. Mikroskopie 33, 80-87.
SPURR, A. R. (1969). A low-viscosity epoxy resin embedding medium for electron microscopy. Journal of Ultrastructure Research 26, 31-43.

UTKILEN, H. C. (1982). Magnesium-limited growth of the cyanobacterium Anacystis nidulans. Journal of General Microbiology 128, 1849-1862.

WEIBEL, E. R. (1969). Stereological principles for morphometry in electron microscopy cytology. International Review of Cytology 26, 235-302. 